\title{
Effects of supplemental irrigation on water consumption characteristics and grain yield in different wheat cultivars
}

\author{
Weiwei Meng1, Zhenwen Yu' ${ }^{1}$, Yongli Zhang ${ }^{1 *}$, Yu Shi ${ }^{1}$, and Dong Wang ${ }^{1}$
}

\begin{abstract}
Shortage of water resources is a major limiting factor for wheat (Triticum aestivum L.) production in the North China Plain . The objectives of this study were to evaluate the effects of supplemental irrigation (SI) on water use characteristics and grain yield of the wheat cultivars 'Jimai 22'and 'Zhouyuan 9369'. Two supplemental irrigation treatment regimens were designed based on target relative soil moisture contents in $0-140 \mathrm{~cm}$ soil layers at jointing rising to $75 \%$ of field capacity (FC) for each cultivar, and at anthesis rising to 65\% and 75\% (W1), and 70\% and 80\% (W2) in 2009-2010 and 2010-2011, respectively. Rain-fed (W0) treatment was used as control. Under W1, grain yield of 'Jimai 22' was 5.22\% higher than that of W2, and water use efficiency (WUE) of 'Zhouyuan 9369' was 4.0\% higher than that under W2. No significant differences in WUE of 'Jimai 22' and grain yield of 'Zhouyuan 9369' were observed for the two treatment regimens in 2009-2010. Grain yield and WUE in W1 were higher than those of W2 for both cultivars in 2010-2011. W1 enhanced soil water consumption compared to W2, especially in the 100-200 cm soil layers, for both cultivars in 2009-2011. Meanwhile, 'Jimai 22' showed higher soil water consumption and ET from anthesis to mature stage, which resulted in increase in grain yield and WUE of 'Jimai 22' by 8.15-21.7\% and 7.75-11.73\% in 2009-2010 and 2010-2011, respectively, compared with 'Zhouyuan 9369'. Thus, our results showed that SI increased the yield and WUE of 'Jimai 22' and W1 was the better treatment regimen.
\end{abstract}

Key words: Grain yield, supplemental irrigation, Triticum aestivum, water use characteristic, water use efficiency, winter wheat cultivars.

\section{INTRODUCTION}

The North China Plain is one of the most important regions for agricultural production in China. Evapotranspiration (ET) during the winter wheat (Triticum aestivum L.) growing season is approximately $400-500 \mathrm{~mm}$ in this region. However, annual precipitation during wheat growth is typically below $200 \mathrm{~mm}$ (Li et al., 2007). In recent years, sustainable development of agriculture in this region has been threatened by water shortages and overexploitation of groundwater (Li et al., 2008; Zhang et al., 2010b). Hence, adoption of water-saving agriculture measures is critical to ensure wheat production and to increase the water use efficiency (WUE) in this region (Wang et al., 2001; Shao et al., 2007).

For maximal wheat yield, irrigation is applied at critical stages of wheat development. However, the recommended irrigation schemes differ across experimental conditions. Xue et al. (2003) found that maximizing wheat yield and WUE requires three applications of irrigation, one each at jointing, booting, and anthesis, totaling $300 \mathrm{~mm}$. Zhang et al. (2004b) recommended three applications at jointing,

${ }^{1}$ Shandong Agricultural University, College of Agronomy, Tai'an 271018, China. "Corresponding author (zhangyl@ sdau.edu.cn).

Received: 2 July 2014.

Accepted: 25 January 2015.

doi:10.4067/S0718-58392015000200011 booting to heading, and anthesis to the early milk stages, with $180 \mathrm{~mm}$ of total irrigation. Li et al. (2010) showed that two applications of $60 \mathrm{~mm}$ irrigation, one each at jointing and heading, increased grain yield and resulted in the highest WUE compared with one and three applications of irrigation during the winter wheat growing season. According to Zhang et al. (2007), irrigation should be applied twice during the wheat growing season-one in the reviving stage and the other in the heading stage, with the optimal irrigation amounts being 60,75, and $90 \mathrm{~mm}$ for furrow irrigated raised bed-planting (FIRB), mulched ridge and furrow planting (MRFP), and conventional flat planting (FP), respectively. The FIRB system with $60 \mathrm{~mm}$ irrigation resulted in higher yield and WUE than both MRFP and FP.

The physiological and genetic bases of high WUE vary significantly across crop varieties (Gupta et al., 2001; Monclus et al., 2009). In monocultures, recent cultivars were found to have significantly higher grain yield and WUE for grain $\left(\mathrm{WUE}_{\mathrm{G}}\right)$ than old cultivars (Song et al., 2009; Fang et al., 2011; Yang et al., 2013), and a stable low yield was observed in the old cultivar with low response to irrigation treatment (Rizza et al., 2012). Zhang et al. (2010a) showed variation in yield and WUE of about $20 \%$ among 16 winter wheat cultivars released between 1998 and 2002, and the ones with higher yield were also generally associated with higher WUE. Selection of watersaving, drought-resistant, higher-yielding cultivars has the potential to improve grain yield and WUE, which is 
critical for water-scarce regions. Many irrigation regimes for wheat production in the North China Plain region have been studied, but most experiments conducted to date have tested the effects of fixed irrigation amounts.

In this study, a new method of recharging soil water via supplemental irrigation (SI) to different target relative water contents in 0-140 cm soil was adopted for different winter wheat cultivars. This study aimed to: (1) determine optimal scheduling of SI in different wheat cultivars; (2) investigate the response of ET, soil water use, grain yield, and WUE to soil water content (SWC) at critical growing stages; and (3) determine differences between two wheat cultivars in ET, soil water use, grain yield, and WUE under different SI treatments. We believe that the results will be highly informative in drafting useful guidelines to optimize agro-management practices for water-saving and high-yielding wheat cultivation.

\section{MATERIALS AND METHODS}

The field experiments were conducted from October 2009 to June 2011 at the experimental station of Shandong Agricultural University (36'17" N, 117'15" E). The station is located in the center of the North China Plain, and the environment is typical and representative of the plain. The mean annual temperature in the study area is $14.1{ }^{\circ} \mathrm{C}$. The average annual rainfall is $660.1 \mathrm{~mm}, 70 \%$ of which occurs between July and September. The agrotype of the field was loam based on the soil classification system of China (CRGCST, 2001), with a composition of $29.6 \%$ clay, $37.3 \%$ silt, and $33.1 \%$ sand, and $\mathrm{pH}$ of 7.6 . The chemical properties of the $0-20 \mathrm{~cm}$ topsoil in the experimental plots, field capacity of the $0-200 \mathrm{~cm}$ soil layers before sowing in each growing season, and rainfall during the 2009-2010 and 2010-2011 growing seasons are shown in Table $1 \mathrm{a}, 1 \mathrm{~b}$, and $1 \mathrm{c}$, respectively.

Two irrigation treatments were designed based on the target relative soil moisture content in the $0-140 \mathrm{~cm}$ soil layers at jointing and anthesis stages for each cultivar rising to $75 \%$ and $65 \%$ of field capacity (FC) (W1) and $75 \%$ and $70 \%$ of FC (W2) in 2009-2010, and $75 \%$ and $75 \%$ of FC (W1) and $75 \%$ and $80 \%$ of FC (W2) in 20102011, respectively. Rain-fed (W0) treatment was used as the control in both growing seasons. The amount of supplemental irrigation (SI) was calculated using Equation [1] (Jalilian et al., 2012):

$$
C I R=100 \gamma b d D_{h}(\theta t-\theta n)
$$

where $C I R(\mathrm{~mm})$ is the amount of SI, $\gamma b d\left(\mathrm{~g} \mathrm{~cm}^{-3}\right)$ is the soil bulk density, $D_{h}(\mathrm{~cm})$ is the depth of the soil layer (140 $\mathrm{cm}$ in this study), $\theta t$ (mg water $\mathrm{g}^{-1}$ dry soil) is the target soil water content (SWC) on a weight basis after SI, and $\theta n$ (mg water $\mathrm{g}^{-1}$ dry soil) is the water content of the soil on a weight basis before irrigation. $\theta t$ was calculated using Equation [2] as follows:

$$
\theta t=\theta \max \theta r / 100
$$

where $\theta \max$ (mg water $\mathrm{g}^{-1}$ dry soil) is the field capacity, and $\theta r(\%)$ is the target relative SWC. Water was sprayed evenly on the experimental plots under pressure. A flow meter (DN50-R80, Juxingwang Inc., Ningbo, China) was used to measure the amount of water applied. The actual relative SWC in the $0-140 \mathrm{~cm}$ soil layers after SI, as well as the amount of SI under different treatments, are shown in Table 2.

The experiment was conducted in a split block design with three replicates, including the wheat cultivars in main block and the irrigation treatments in secondary block in a $2 \mathrm{~m} \times 5 \mathrm{~m}$ plot. Between two adjacent irrigation plots, a $1.5 \mathrm{~m}$-wide unirrigated zone was maintained to minimize the effects of adjacent plots.

The winter wheat cultivars 'Jimai 22' (the most widely planted commercial cultivar in the North China Plain with strong resistance and high yield) and 'Zhouyuan 9369' (a widely planted commercial specialty cultivar in Shandong province with strong high quality gluten) were used in each growing season. Wheat seeds were sown at a density of 180 plants $\mathrm{m}^{-2}$ on 7 October 2009 and 7 October 2010. All plots were supplied with $240 \mathrm{~kg} \mathrm{~N}$ ha $^{-1}, 112.5 \mathrm{~kg} \mathrm{P}_{2} \mathrm{O}_{5} \mathrm{ha}^{-1}$, and $112.5 \mathrm{~kg} \mathrm{~K}_{2} \mathrm{O} \mathrm{ha}^{-1}$. All $\mathrm{P}$ and $\mathrm{K}$ fertilizers and $105 \mathrm{~kg} \mathrm{ha}^{-1}$

Table 1. Properties in the $0-20 \mathrm{~cm}$ topsoil layer (a), field water capacity of 0-200 $\mathrm{cm}$ soil layers (b), and rainfall (mm) during wheat growth (c) in 2009-2010 and 2010-2011.

\begin{tabular}{|c|c|c|c|c|c|}
\hline Years & Total N & $\begin{array}{c}\text { Alkali- } \\
\text { hydrolyzable N }\end{array}$ & Available K & Available P & $\begin{array}{l}\text { Organic } \\
\text { matter }\end{array}$ \\
\hline & $\mathrm{g} \mathrm{kg}^{-1}$ & & $-\mathrm{mg} \mathrm{kg}^{-1}$ & 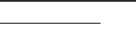 & $\mathrm{g} \mathrm{kg}^{-1}$ \\
\hline 2009-2010 & 1.2 & 93.33 & 110.46 & 31.80 & 16.9 \\
\hline $2010-2011$ & 1.3 & 105.01 & 105.75 & 30.24 & 18.6 \\
\hline
\end{tabular}

a)

b)

\begin{tabular}{lcccccccccc}
\hline & \multicolumn{10}{c}{ Soil layers $(\mathrm{cm})$} \\
\cline { 2 - 10 } Years & $0-20$ & $20-40$ & $40-60$ & $60-80$ & $80-100$ & $100-120$ & $120-140$ & $140-160$ & $160-180$ & $180-200$ \\
\hline $2009-2010$ & 16.21 & 17.31 & 19.24 & 18.83 & 19.80 & 22.52 & 25.56 & 27.30 & 24.96 & 25.58 \\
$2010-2011$ & 16.34 & 17.84 & 19.22 & 19.84 & 21.01 & 22.45 & 24.11 & 29.70 & 27.06 & 27.43 \\
\hline
\end{tabular}

c)

\begin{tabular}{lrrrrrrrrc}
\hline & \multicolumn{10}{c}{ Months } \\
\cline { 2 - 9 } Years & 10 & 11 & 12 & 1 & 2 & 3 & 4 & 5 \\
\hline $2009-2010$ & 12.9 & 21.3 & 6.2 & 3.2 & 18.9 & 14.8 & 20.5 & 42.0 \\
$2010-2011$ & 2.5 & 0.0 & 0.2 & 0.0 & 24.0 & 2.6 & 10.4 & 132.0 & 0.3 \\
\hline
\end{tabular}


Table 2. Target relative soil water content $\left(\boldsymbol{\theta}_{\mathrm{tr}}, \%\right.$ field water capacity) and the actual relative soil water content after supplemental irrigation $\left(\theta_{\mathrm{ar}}, \%\right.$ field water capacity) in the $0-140 \mathrm{~cm}$ soil layer for irrigation treatments (W0, W1, W2) at different stages of plant growth in $2009-2010$ and 2010-2011. The amount of supplemental irrigation (CIR, $\mathrm{mm}$ ) is also indicated.

\begin{tabular}{|c|c|c|c|c|c|c|c|c|c|}
\hline \multirow[b]{2}{*}{ Years } & \multirow[b]{2}{*}{ Cultivars } & \multirow[b]{2}{*}{ Treatments } & \multicolumn{3}{|c|}{ Irrigation at jointing stage } & \multicolumn{3}{|c|}{ Irrigation at anthesis stage } & \multirow[b]{2}{*}{ Total CIR } \\
\hline & & & $\theta_{\mathrm{tr}}$ & $\theta_{\mathrm{ar}}$ & CIR & $\theta_{\mathrm{tr}}$ & $\theta_{\mathrm{ar}}$ & CIR & \\
\hline \multirow[t]{6}{*}{ 2009-2010 } & Jimai 22 & W0 & - & 62.14 & 0.00 & - & 53.45 & 0.00 & 0.00 \\
\hline & & W1 & 75 & 76.24 & 70.12 & 65 & 63.72 & $21.82 b$ & $91.94 b$ \\
\hline & & W2 & 75 & 76.24 & 70.12 & 70 & 69.46 & $49.07 \mathrm{a}$ & $119.19 \mathrm{a}$ \\
\hline & Zhouyuan 9369 & W0 & - & 62.54 & 0.00 & - & 53.35 & 0.00 & 0.00 \\
\hline & & W1 & 75 & 76.02 & 67.95 & 65 & 62.44 & $19.52 b$ & $87.47 b$ \\
\hline & & W2 & 75 & 76.02 & 67.95 & 70 & 70.68 & $46.78 \mathrm{a}$ & $114.73 a$ \\
\hline \multirow[t]{6}{*}{ 2010-2011 } & Jimai 22 & W0 & - & 59.88 & 0.00 & - & 66.79 & 0.00 & 0.00 \\
\hline & & $\mathrm{W} 1$ & 75 & 73.27 & 85.88 & 75 & 74.95 & 0.00 & $85.88 b$ \\
\hline & & W2 & 75 & 73.27 & 85.88 & 80 & 79.72 & 27.53 & $113.40 \mathrm{a}$ \\
\hline & Zhouyuan 9369 & W0 & - & 63.10 & 0.00 & - & 70.19 & 0.00 & 0.00 \\
\hline & & W1 & 75 & 77.92 & 64.57 & 75 & 75.26 & 0.00 & $64.57 \mathrm{c}$ \\
\hline & & W2 & 75 & 77.92 & 64.57 & 80 & 77.24 & 25.83 & $90.39 b$ \\
\hline
\end{tabular}

Values followed by different letters within the same column in each growing season are significantly different at 0.05 probability level.

$\mathrm{N}$ fertilizer were applied pre-sowing, and the remaining $\mathrm{N}$ fertilizer was top-dressed at jointing. The fertilizers used were urea $(46 \% \mathrm{~N})$, ammonium dibasic phosphate $(46 \%$ $\mathrm{P}_{2} \mathrm{O}_{5}$ and $\left.18 \% \mathrm{~N}\right)$, and potassium sulfate $\left(52 \% \mathrm{~K}_{2} \mathrm{O}\right)$.

ET was calculated using the water balance Equation [3] (Miranzadeh et al., 2011):

$$
E T=\left(P+I+S_{G}\right)-(D+R)-\Delta S
$$

where $P$ is the growing seasonal rainfall $(\mathrm{mm}), I$ is irrigation $(\mathrm{mm}), S_{\mathrm{G}}$ is the groundwater contribution to plant available water $(\mathrm{mm}), D$ is downward drainage out of the root zone (mm), $R$ is surface runoff $(\mathrm{mm})$, and $\Delta S$ is the change in soil water stored in the upper $200 \mathrm{~cm}$ of the soil between sowing and maturity $(\mathrm{mm})$. In this experiment, the groundwater was $15 \mathrm{~m}$ below the surface, and runoff was prevented from the experimental plots. Thus, $S_{\mathrm{G}}, D$, and $R$ were negligible.

Oven drying was used to measure the SWC every 20 $\mathrm{cm}$ up to a depth of $200 \mathrm{~cm}$, and these values were used to calculate soil water consumption $(\Delta S)$. Soil core samples were collected randomly using a steel sampling tube (50 $\mathrm{mm}$ diameter) driven manually into the soil. The soil cores were weighed to obtain the current weight, ovendried at $105^{\circ} \mathrm{C}$ for $48 \mathrm{~h}$, and re-weighed to determine the gravimetric water content. Measurements were obtained at sowing, jointing, anthesis, and maturity (Gan et al., 2000).

Grain yields were determined by manually harvesting $2 \mathrm{~m}^{2}$ samples of each plot, and expressed at $12.5 \%$ moisture content (Xue et al., 2006).

The WUE was calculated based on Equation [4] (Sun et al., 2006; Liu et al., 2011).

$$
\text { WUE }=\text { Grain yield/ET }
$$

Irrigation benefit (IB) was calculated using Equation [5] (Yu et al., 1995; Duivenboodew et al., 2000):

$$
I B=\left(Y_{I}-Y_{0}\right) / I
$$

where $Y_{I}$ is the grain yield of irrigation treatment $\left(\mathrm{kg} \mathrm{ha}^{-1}\right)$, $Y_{0}$ is the grain yield of no irrigation treatment, and $I$ is the amount of irrigation $(\mathrm{mm})$.

Statistical analysis was performed using SPSS Version 10.0 (SPSS for Windows, IBM, Armonk, New York, USA). All data are presented as the mean of three replicates. ANOVA was used to establish significant differences, and treatment means were compared using the least significant differences $(P=0.05)$.

\section{RESULTS}

\section{Grain yield, WUE, and IB}

W0 treatment had the lowest grain yield and WUE for both cultivars in both growing seasons (Table 3). In 2009-2010, grain yield in with W1 treatment significantly increased by $5.22 \%$ than that in W2 for 'Jimai 22', but there was no significant differences in grain yield for 'Zhouyuan 9369' between W1 and W2. W1 treatment showed no significant increase in WUE for 'Jimai 22', but resulted in 4.0\% increase in WUE for 'Zhouyuan 9369' compare to W2 treatment. In 2010-2011, the grain yield, WUE, and IB in W1 treatment were higher than those in W2 for both cultivars. These results indicate that W1 treatment provided the appropriate amount of water for both cultivars in both growing seasons.

'Jimai 22' showed significant increases in grain yield and WUE compared with 'Zhouyuan 9369' under the same irrigation conditions in both growing seasons (Table 3). In 2009-2010, grain yield and WUE increased by $12.26 \%$ and $7.75 \%$, respectively, under $\mathrm{W} 1$, and by

Table 3. Effects of different treatments on grain yield, water use efficiency (WUE) and irrigation benefit (IB) in 2009-2010 and 20102011.

\begin{tabular}{lccccc}
\hline Years & Cultivars & Treatments & $\begin{array}{c}\text { Grain } \\
\text { yield }\end{array}$ & WUE & IB \\
\hline \multirow{2}{*}{ 2009-2010 } & \multirow{3}{*}{ Jimai 22 } & W0 & $7474.68 \mathrm{~d}$ & $\begin{array}{c}\mathrm{kg} \mathrm{ha}^{-1} \\
\mathrm{~kg} \mathrm{ha}^{-1} \mathrm{~mm}^{-1}\end{array}$ & $\mathrm{~kg} \mathrm{ha}^{-1} \mathrm{~mm}^{-1}$ \\
& & W1 & $9387.25 \mathrm{c}$ & $21.55 \mathrm{a}$ & $20.80 \mathrm{a}$ \\
& & W2 & $8921.75 \mathrm{~b}$ & $20.93 \mathrm{ab}$ & $12.14 \mathrm{c}$ \\
& \multirow{3}{*}{ Zhouyuan 9369 } & W0 & $6868.50 \mathrm{e}$ & $18.09 \mathrm{~d}$ & \\
& & W1 & $8362.41 \mathrm{c}$ & $20.00 \mathrm{~b}$ & $17.08 \mathrm{~b}$ \\
& & W2 & $8249.20 \mathrm{c}$ & $19.23 \mathrm{c}$ & $12.03 \mathrm{c}$ \\
& \multirow{2}{*}{ Jimai 22 } & W0 & $7069.25 \mathrm{~d}$ & $19.47 \mathrm{c}$ & \\
& & W1 & $9076.45 \mathrm{a}$ & $21.49 \mathrm{a}$ & $23.30 \mathrm{~b}$ \\
& & W2 & $8743.10 \mathrm{~b}$ & $20.19 \mathrm{~b}$ & $14.76 \mathrm{~d}$ \\
& \multirow{2}{*}{ Zhouyuan 9369 } & W0 & $5665.90 \mathrm{e}$ & $16.32 \mathrm{e}$ & \\
& & W1 & $7546.00 \mathrm{c}$ & $19.65 \mathrm{c}$ & $29.12 \mathrm{a}$ \\
& & W2 & $7183.90 \mathrm{~d}$ & $18.07 \mathrm{~d}$ & $16.79 \mathrm{c}$ \\
\hline
\end{tabular}

Values followed by different letters within the same column in each growing season are significantly different at 0.05 probability level. 
$8.15 \%$ and $8.84 \%$, respectively, under W2 for 'Jimai 22' compared to 'Zhouyuan 9369'. The IB for 'Jimai 22' was significantly higher by $21.78 \%$ compared to that for 'Zhouyuan 9369' under W1 condition, and no significant difference in IB was observed between the two cultivars under W2 condition. In 2010-2011, grain yield and WUE increased by $20.28 \%$ and $9.36 \%$, respectively, under $\mathrm{W} 1$, and by $21.7 \%$ and $11.73 \%$, respectively, under W2 for 'Jimai 22' compared to 'Zhouyuan 9369'. The IB for 'Jimai 22' was significantly lower than that for 'Zhouyuan 9369' under W1 and W2 conditions.

Irrigation, soil water consumption, and total ET during the winter wheat growing season

In both growing seasons for both cultivars, W0 treatment had the highest soil water consumption and ratio to ET, but its ET was the lowest (Table 4). No significant difference in ET was observed between W1 and W2 treatments, but W1 treatment had lower SI and higher soil water consumption. This result indicates that $\mathrm{W} 1$ treatment decreased the irrigation amount and increased soil water consumption compared with W2, but no increase in ET occurred in both cultivars. The ratio of precipitation to ET was not found to be significantly different between the two treatments for both cultivars in both growing seasons. From 2009 to 2010, ET of 'Jimai 22' was significantly higher than that of 'Zhouyuan 9369' under W1 condition, and soil water consumption showed similar changes.

From 2010 to 2011, ET for 'Jimai 22' showed a significant increase compared with 'Zhouyuan 9369' under W1 and W2 treatments, and soil water consumption exhibited the same trend. These results show that 'Jimai 22' could utilize more soil water under different precipitation rates, especially with lower rainfall before jointing (only $26.7 \mathrm{~mm}$ ).

ET at different stages and its consumption percentage The daily consumption rates from jointing to anthesis were the highest among all treatments conditions for both cultivars, followed by those from anthesis to maturity. The daily consumption rates of all treatments in these two stages were higher than $3.16 \mathrm{~mm}$ (Table 5). The daily consumption rates before jointing were the lowest at less than $1 \mathrm{~mm}$. This finding indicates that water consumption before jointing was low, so low irrigation amount is appropriate for this stage. However, jointing to anthesis

Table 4. Sources of water consumption and their percentage of total water consumption amount under different treatments in 2009-2010 and $2010-2011$. Where $\Delta S$ is the change in soil water stored in the upper $200 \mathrm{~cm}$ of the soil between sowing and maturity $(\mathrm{mm})$.

\begin{tabular}{|c|c|c|c|c|c|c|c|c|}
\hline \multirow{2}{*}{$\begin{array}{l}\text { Years and } \\
\text { cultivars }\end{array}$} & \multirow[b]{2}{*}{ Treatments } & \multirow{2}{*}{$\begin{array}{c}\text { Total water consumption } \\
\text { amount }(\mathrm{mm})\end{array}$} & \multicolumn{3}{|c|}{ Amount (mm) } & \multicolumn{3}{|c|}{ Percentage $(\%)$} \\
\hline & & & Irrigation & Precipitation & $\Delta S$ & Irrigation & Precipitation & $\Delta S$ \\
\hline \multicolumn{9}{|l|}{$2009-2010$} \\
\hline \multirow[t]{3}{*}{ Jimai 22} & W0 & $383.88 \mathrm{c}$ & 0.00 & 149.1 & $234.78 \mathrm{a}$ & 0.00 & $38.84 a$ & $61.16 \mathrm{a}$ \\
\hline & W1 & $435.70 \mathrm{a}$ & $91.94 b$ & 149.1 & $194.66 b$ & $21.10 \mathrm{~b}$ & $34.22 b$ & $44.68 b$ \\
\hline & W2 & $429.99 \mathrm{ab}$ & $119.19 \mathrm{a}$ & 149.1 & $161.70 \mathrm{~d}$ & $27.72 \mathrm{a}$ & $34.68 \mathrm{~b}$ & $37.61 \mathrm{c}$ \\
\hline \multirow[t]{3}{*}{ Zhouyuan 9369} & W0 & $379.77 \mathrm{c}$ & 0.00 & 149.1 & $230.67 \mathrm{a}$ & 0.00 & $39.26 a$ & $60.74 a$ \\
\hline & W1 & $418.12 b$ & $87.47 \mathrm{c}$ & 149.1 & $181.55 \mathrm{c}$ & $20.92 b$ & $35.66 \mathrm{~b}$ & $43.42 b$ \\
\hline & W2 & $428.98 \mathrm{ab}$ & $114.73 \mathrm{a}$ & 149.1 & $165.15 \mathrm{~d}$ & $26.74 a$ & $34.76 b$ & $38.50 \mathrm{c}$ \\
\hline \multicolumn{9}{|l|}{$2010-2011$} \\
\hline \multirow[t]{3}{*}{ Jimai 22} & W0 & $373.32 \mathrm{c}$ & 0.00 & 172 & $201.32 \mathrm{a}$ & 0.00 & $46.07 \mathrm{~b}$ & $53.93 \mathrm{a}$ \\
\hline & W1 & $422.44 a$ & $86.15 b$ & 172 & $164.29 \mathrm{c}$ & $20.39 \mathrm{c}$ & $40.72 d$ & $38.89 \mathrm{c}$ \\
\hline & W2 & $433.02 \mathrm{a}$ & $113.40 \mathrm{a}$ & 172 & $147.61 d$ & $26.19 \mathrm{a}$ & $39.72 d$ & $34.09 \mathrm{~d}$ \\
\hline \multirow[t]{3}{*}{ Zhouyuan 9369} & W0 & $347.21 \mathrm{~d}$ & 0.00 & 172 & $175.21 b$ & 0.00 & $49.54 \mathrm{a}$ & $50.46 \mathrm{~b}$ \\
\hline & W1 & $384.02 \mathrm{bc}$ & $64.57 \mathrm{c}$ & 172 & $147.45 \mathrm{~d}$ & $16.81 \mathrm{~d}$ & $44.79 b c$ & $38.40 \mathrm{c}$ \\
\hline & W2 & $397.45 b$ & $90.39 \mathrm{~b}$ & 172 & $135.06 \mathrm{e}$ & $22.74 b$ & $43.28 \mathrm{c}$ & $33.98 \mathrm{~d}$ \\
\hline
\end{tabular}

Values followed by different letters within the same column in each growing season are significantly different at 0.05 probability level.

Table 5. Water consumption amount (CA), daily consumption (CD) and its consumption percentage (CP) at different growth stages of different treatment in 2009-2010 and 2010-2011.

\begin{tabular}{|c|c|c|c|c|c|c|c|c|c|c|}
\hline \multirow{2}{*}{$\begin{array}{l}\text { Years and } \\
\text { cultivars }\end{array}$} & \multirow[b]{2}{*}{ Treatments } & \multicolumn{3}{|c|}{ Sowing to jointing } & \multicolumn{3}{|c|}{ Jointing to anthesis } & \multicolumn{3}{|c|}{ Anthesis to maturity } \\
\hline & & $\mathrm{CA}$ & $\mathrm{CD}$ & $\mathrm{CP}$ & CA & $\mathrm{CD}$ & $\mathrm{CP}$ & $\mathrm{CA}$ & CD & $\mathrm{CP}$ \\
\hline & & -1 & 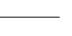 & $\%$ & - & - & $\%$ & $-\mathrm{n}$ & - & $\%$ \\
\hline \multicolumn{11}{|l|}{ 2009-2010 } \\
\hline \multirow[t]{3}{*}{ Jimai 22} & W0 & $144.13 a$ & $0.80 \mathrm{a}$ & $37.55 \mathrm{a}$ & $122.65 b$ & $4.09 \mathrm{~b}$ & $31.95 \mathrm{~b}$ & $117.10 \mathrm{~d}$ & $3.16 \mathrm{~d}$ & $30.51 \mathrm{~d}$ \\
\hline & $\mathrm{W} 1$ & $144.13 \mathrm{a}$ & $0.80 \mathrm{a}$ & $33.08 \mathrm{~b}$ & $138.23 \mathrm{a}$ & $4.61 \mathrm{a}$ & $31.73 b$ & $153.34 \mathrm{a}$ & $4.14 \mathrm{a}$ & $35.19 \mathrm{a}$ \\
\hline & W2 & $144.13 a$ & $0.80 \mathrm{a}$ & $33.52 b$ & $138.23 \mathrm{a}$ & $4.61 \mathrm{a}$ & $32.15 b$ & $147.62 \mathrm{ab}$ & $3.99 \mathrm{ab}$ & $34.33 \mathrm{ab}$ \\
\hline \multirow[t]{3}{*}{ Zhouyuan 9369} & W0 & $142.81 \mathrm{a}$ & $0.79 \mathrm{a}$ & $37.60 \mathrm{a}$ & $109.18 \mathrm{c}$ & $3.64 \mathrm{c}$ & $28.75 \mathrm{c}$ & $127.77 \mathrm{c}$ & $3.45 \mathrm{c}$ & $33.65 \mathrm{bc}$ \\
\hline & $\mathrm{W} 1$ & $142.81 \mathrm{a}$ & $0.79 \mathrm{a}$ & $34.16 b$ & $141.47 \mathrm{a}$ & $4.72 \mathrm{a}$ & $33.83 \mathrm{a}$ & $133.84 \mathrm{bc}$ & $3.62 \mathrm{bc}$ & $32.01 \mathrm{c}$ \\
\hline & W2 & $142.81 \mathrm{a}$ & $0.79 \mathrm{a}$ & $33.29 \mathrm{~b}$ & $141.47 \mathrm{a}$ & $4.72 \mathrm{a}$ & $32.98 \mathrm{ab}$ & $144.70 b$ & $3.91 \mathrm{~b}$ & $33.73 b c$ \\
\hline \multicolumn{11}{|l|}{$2010-2011$} \\
\hline \multirow[t]{3}{*}{ Jimai 22} & W0 & $141.28 \mathrm{a}$ & $0.78 \mathrm{a}$ & $37.85 \mathrm{a}$ & $108.49 \mathrm{c}$ & $3.62 \mathrm{c}$ & $29.06 \mathrm{c}$ & $123.54 \mathrm{c}$ & $3.34 \mathrm{c}$ & $33.09 \mathrm{c}$ \\
\hline & $\mathrm{W} 1$ & $141.28 \mathrm{a}$ & $0.78 \mathrm{a}$ & $33.44 b$ & $135.78 \mathrm{a}$ & $4.53 \mathrm{a}$ & $32.14 b$ & $145.37 \mathrm{ab}$ & $3.93 \mathrm{ab}$ & $34.41 \mathrm{bc}$ \\
\hline & W2 & $141.28 \mathrm{a}$ & $0.78 \mathrm{a}$ & $32.63 b c$ & $135.78 \mathrm{a}$ & $4.53 \mathrm{a}$ & $31.36 \mathrm{~b}$ & $155.95 \mathrm{a}$ & $4.21 \mathrm{a}$ & $36.02 \mathrm{ab}$ \\
\hline \multirow[t]{3}{*}{ Zhouyuan 9369} & W0 & $110.74 b$ & $0.61 b$ & $31.89 \mathrm{c}$ & $114.97 \mathrm{~b}$ & $3.83 \mathrm{~b}$ & $33.11 b$ & $121.51 \mathrm{c}$ & $3.28 \mathrm{c}$ & $35.00 \mathrm{~b}$ \\
\hline & W1 & $110.74 b$ & $0.61 \mathrm{~b}$ & $28.84 d$ & $139.21 \mathrm{a}$ & $4.64 \mathrm{a}$ & $36.25 \mathrm{a}$ & $134.07 \mathrm{~b}$ & $3.62 \mathrm{~b}$ & $34.91 b$ \\
\hline & W2 & $110.74 b$ & $0.61 b$ & $27.86 \mathrm{~d}$ & $139.21 \mathrm{a}$ & $4.64 \mathrm{a}$ & $35.03 \mathrm{a}$ & $147.51 \mathrm{ab}$ & 3.99ab & $37.11 \mathrm{a}$ \\
\hline
\end{tabular}

Values followed by different letters within the same column in each growing season are significantly different at 0.05 probability level. 
and anthesis to maturity were key stages with high water needs, so SI is appropriate for these stages.

ET from jointing to anthesis $\left(\mathrm{ET}_{\mathrm{J}-\mathrm{A}}\right)$ and anthesis to mature $\left(\mathrm{ET}_{\mathrm{A}-\mathrm{M}}\right)$, and daily consumption in these two stages in the W0 treatment group were significantly lower than those in W1 and W2 treatments groups for both cultivars in both growing seasons (Table 5). From 2009 to 2010 , ET from anthesis to maturity $\left(\mathrm{ET}_{\mathrm{A}-\mathrm{M}}\right)$ and its consumption percentage to ET in W1 treatment for 'Jimai 22' were higher than those in W2. For 'Zhouyuan 9369', $\mathrm{ET}_{\mathrm{A}-\mathrm{M}}$ under $\mathrm{W} 1$ treatment was lower than that under $\mathrm{W} 2$, and no significant difference in the consumption percentage of $\mathrm{ET}_{\mathrm{A}-\mathrm{M}}$ to $\mathrm{ET}$ was observed between $\mathrm{W} 1$ and W2 treatments. From 2010 to 2011, W2 treatment had the highest $\mathrm{ET}_{\mathrm{A}-\mathrm{M}}$, daily consumption, and consumption percentage of $\mathrm{ET}_{\mathrm{A}-\mathrm{M}}$ to $\mathrm{ET}$ for both cultivars. The results showed that increasing the target relative soil moisture content in the $0-140 \mathrm{~cm}$ soil layers at jointing and anthesis increased $\mathrm{ET}_{\mathrm{J}-\mathrm{A}}$ and $\mathrm{ET}_{\mathrm{A}-\mathrm{M}}$, which resulted in higher $\mathrm{ET}$ for both cultivars.

In both growing seasons, $\mathrm{ET}_{\mathrm{A}-\mathrm{M}}$ for 'Jimai 22' was significantly higher than that for 'Zhouyuan 9369' under W1 treatment. This indicates that 'Jimai 22' had a higher $\mathrm{ET}_{\mathrm{A}-\mathrm{M}}$ than 'Zhouyuan 9369', which may explain why 'Jimai 22' had higher ET.

Soil water consumption amount in different soil layers Soil water consumption under W0 treatment in various soil layers for both cultivars was significantly higher than those for W1 and W2 treatments in both growing seasons (Table 6). From 2009 to 2010, soil water consumption in the $20-200 \mathrm{~cm}$ soil layers under W1 treatment for 'Jimai 22' was significantly higher than that under W2 treatment. For 'Zhouyuan 9369', soil water consumption in the 100$200 \mathrm{~cm}$ soil layers under W1 treatment was significantly higher than that under W2 treatment. From 2010 to 2011, soil water consumption in the $0-200 \mathrm{~cm}$ soil layers under W1 treatment for 'Jimai 22' was significantly higher than that under W2 treatment. For 'Zhouyuan 9369', soil water consumption in the $60-200 \mathrm{~cm}$ soil layers under W1 treatment was significantly higher than that under W2 treatment. These results show that $\mathrm{W} 1$ treatment increased soil water consumption in deep soil layers, which resulted in higher soil water consumption by both cultivars in both growing seasons.

From 2009 to 2010 , soil water consumption in the 20$140 \mathrm{~cm}$ soil layers for 'Jimai 22' was significantly higher than that for 'Zhouyuan 9369' under W0 and W1 conditions (Table 6). From 2010 to 2011, soil water consumption in the $60-200 \mathrm{~cm}$ soil layers for 'Jimai 22' was significantly higher than that for 'Zhouyuan 9369' under the three irrigation conditions. These results indicate that 'Jimai 22' had high capacity for utilizing soil water from deep soil layers in different precipitation years.

\section{DISCUSSION}

Wheat growth is affected by SWC, but irrigation at $100 \%$ of field capacity does not necessarily lead to higher yields (Saeedipour and Moradi, 2012). Moreover, scarcity of water resources and low irrigation water use efficiency pose serious threats to wheat production in many parts of the world (Marano et al., 2012; Pask and Reynolds, 2013; Chebil et al., 2014). Previous studies have shown that moderate deficit in irrigation or water stress from the start of growth to the jointing stage can reduce water consumption with no significant reduction in wheat yields, effectively increasing the WUE (Zhang et al., 2004a; Zhang et al., 2006; Yang et al., 2006; Fereres and Soriano, 2007; Du et al., 2010; Karrou et al., 2012). Dong et al. (2011) found that total irrigation water amounts of $120-150 \mathrm{~mm}$ at jointing and anthesis produced grain yield of 7213.6-7586.7 $\mathrm{kg} \mathrm{ha}^{-1}$ and WUE of 19.7-21.4 kg $\mathrm{ha}^{-1} \mathrm{~mm}^{-1}$ under the condition of adequate soil moisture before sowing. Therefore, it is essential to develop the most suitable irrigation scheme to produce optimum plant yields under limited water supplies for different ecological regions (Zhang et al., 2013). The present study adopted a new method, in which the amount of irrigation water was calculated based on measurement of soil moisture

Table 6. Soil water consumption amount in $0-200 \mathrm{~cm}$ soil layers of the whole growth of wheat under different treatments in $2009-2010$ and 2010-2011 (mm).

\begin{tabular}{|c|c|c|c|c|c|c|c|}
\hline \multirow[b]{2}{*}{ Years } & \multirow[b]{2}{*}{ Cultivars } & \multirow[b]{2}{*}{ Treatments } & \multicolumn{5}{|c|}{ Soil layers (cm) } \\
\hline & & & $0-20$ & $20-60$ & $60-100$ & $100-140$ & $140-200$ \\
\hline \multicolumn{8}{|c|}{ 2009-2010 } \\
\hline & Jimai 22 & W0 & $27.53 \mathrm{a}$ & $65.39 \mathrm{a}$ & $57.77 \mathrm{a}$ & $60.33 \mathrm{a}$ & $23.77 b$ \\
\hline & & W1 & $25.71 b$ & $60.48 b$ & $52.29 \mathrm{~b}$ & $46.80 \mathrm{c}$ & $9.39 \mathrm{~d}$ \\
\hline & & $\mathrm{W} 2$ & $24.97 \mathrm{~b}$ & $55.77 \mathrm{c}$ & $48.69 \mathrm{c}$ & $26.95 f$ & $1.64 f$ \\
\hline & Zhouyuan 9369 & W0 & $27.66 \mathrm{a}$ & $63.08 \mathrm{ab}$ & $53.84 \mathrm{~b}$ & $54.03 \mathrm{~b}$ & $32.06 \mathrm{a}$ \\
\hline & & W1 & $25.94 b$ & $57.53 \mathrm{c}$ & $44.00 \mathrm{~d}$ & $39.19 \mathrm{~d}$ & $14.89 \mathrm{c}$ \\
\hline & & W2 & $25.52 b$ & $57.03 \mathrm{c}$ & $44.13 d$ & $31.16 \mathrm{e}$ & $7.31 \mathrm{e}$ \\
\hline \multicolumn{8}{|c|}{$2010-2011$} \\
\hline & Jimai 22 & W0 & $26.98 \mathrm{a}$ & $46.77 \mathrm{a}$ & $48.52 \mathrm{a}$ & $52.88 \mathrm{a}$ & $26.17 \mathrm{a}$ \\
\hline & & W1 & $26.70 \mathrm{a}$ & $45.54 \mathrm{a}$ & $37.15 d$ & $33.91 \mathrm{bc}$ & $20.99 \mathrm{c}$ \\
\hline & & $\mathrm{W} 2$ & $23.80 \mathrm{~b}$ & $39.32 b$ & $39.27 \mathrm{c}$ & $29.05 d$ & $16.17 \mathrm{~d}$ \\
\hline & Zhouyuan 9369 & W0 & $27.77 \mathrm{a}$ & $46.65 a$ & $41.71 b$ & $35.43 b$ & $23.65 b$ \\
\hline & & W1 & $26.66 \mathrm{a}$ & $37.90 \mathrm{~b}$ & $35.05 \mathrm{e}$ & $32.37 \mathrm{c}$ & $15.47 \mathrm{~d}$ \\
\hline & & $\mathrm{W} 2$ & $24.11 b$ & $37.70 \mathrm{~b}$ & $36.93 d$ & $27.58 \mathrm{e}$ & $8.75 \mathrm{e}$ \\
\hline
\end{tabular}

Values followed by different letters within the same column in each growing season are significantly different at 0.05 probability level. 
content to achieve different target SWCs in a soil profile of $0-140 \mathrm{~cm}$ at jointing and anthesis of wheat. The results showed that the highest grain yields were obtained under W1 treatment in both 'Jimai22' and 'Zhongyuan9369' wheat cultivars. The same trend was observed for WUE under W1 treatment from 2009 to 2011. The grain yield of water-sensitive wheat cultivars decrease significantly compared with drought-resistant cultivars under water deficit conditions (Saeedipour, 2011). In this study, wheat 'Jimai 22' showed higher grain yield and WUE compared with 'Zhouyuan 9369' in different rainfall years in both growing seasons, suggesting that 'Jimai 22' is a watersaving cultivar with high and stable yield. This indicated that appropriate SI after jointing could result in higher yield and WUE in water-saving wheat cultivars. The amount of SI used in this study was based on the SWC before irrigation, which reflected precipitation and crop water consumption. Taken together, our results indicate that this new method can be used to achieve higher water efficiency and yield.

Total ET of wheat consists mainly of precipitation, irrigation, and soil water consumption. Sun et al. (2006) showed that ET is linearly related to the amount of irrigation. A negative correlation exists between soil water consumption and irrigation water consumption (Wang et al., 2006). Moderate water deficit can increase soil water consumption and rainfall utilization in wheat, but reduce the total ET of wheat (Panda et al., 2003; Sun et al., 2006). In the present study, soil water consumption and percentage of soil water consumption and precipitation relative to total water consumption decreased in two different wheat cultivars. The amount of irrigation and its percentage increased with increase in SI level. This result is consistent with that of previous studies (Sun et al., 2006; Wang et al., 2006). W1 treatment, which resulted in lower SWC in 0-140 cm soil at anthesis, demonstrated higher soil water consumption than $\mathrm{W} 2$ treatment, which produced the highest SWC 0-140 cm soil at anthesis. The ET of W1 treatment did not decrease significantly compared with that of W2 treatment. This result may be due to increase in SI level, which significantly reduced soil water consumption under W2 treatment. No significant difference in ET and soil water consumption was observed between the two cultivars from 2009 to 2010 , but this was not the case from 2010 to 2011 (precipitation was only $31.4 \mathrm{~mm}$ before jointing stage, but rose to $117.7 \mathrm{~mm}$ between jointing and anthesis). Both ET and soil water consumption of 'Jimai 22' were significantly higher than those of 'Zhouyuan 9369' in all treatments conditions. Thus, different cultivars exhibited different water consumption levels. Our results suggest that cultivars with higher utilization efficiency of soil water should be selected because they are also more conducive to saving irrigation water.

Water extraction from $60 \mathrm{~cm}$ surface is highest under maximum irrigation treatment $(240 \mathrm{~mm})$, but limited irrigation $(120 \mathrm{~mm})$ results in high soil water extraction from the 90-120 cm soil layers compared with maximum irrigation treatment (Lenka et al., 2009). According to $\mathrm{Li}$ et al. (2010), irrigation during the later part of the winter wheat growing season and increase in irrigation frequency decreases the amount of available soil water. In this study, W0 treatment promoted the absorption utilization of soil water storage in the $0-200 \mathrm{~cm}$ soil layers by wheat. W1 treatment resulted in high soil water consumption in the 100-200 cm soil layers compared with W2 treatment. This finding suggests that SI based on relatively low water contents at anthesis resulted in higher utilization of deep soil water for both cultivars. Wheat 'Jimai 22' utilized more soil water in the $60-140 \mathrm{~cm}$ soil layers compared with wheat 'Zhouyuan 9369' under W1 condition in different precipitation years. Thus, 'Jimai 22' with high grain yield had higher capacity for efficient use of soil water in deep soil layers.

\section{CONCLUSIONS}

The new irrigation scheme of recharging soil water at critical developmental stages of wheat by supplemental irrigation (SI) to different target relative water contents in 0-140 $\mathrm{cm}$ soil can produce high yield and save irrigation water in different winter wheat cultivars. In this study, suitable supplemental irrigation applied at critical growing stages (rising SWC to $65 \%$ or $75 \%$ of field capacity at anthesis) based on target relative soil moisture content of $75 \%$ in the $0-140 \mathrm{~cm}$ soil layers at jointing after SI improved winter wheat yield, water use efficiency (WUE) and irrigation benefit (IB) in different cultivars. Moreover, the yield and water consumption characteristics of two winter wheat cultivars under supplemental irrigation were different. Hence, increasing soil water content in the 0-140 $\mathrm{cm}$ soil layers to a suitable level during critical growing stages of wheat can be an effective strategy to deal with shortage of water in the North China Plain. Finally, our results indicate that the winter wheat cultivar 'Jimai 22' is a high-yielding cultivar with higher WUE compared to 'Zhouyuan 9369'.

\section{ACKNOWLEDGEMENTS}

This study was supported for the National Natural Science Foundation of China (31171498) and the project of Technology System in Modern Wheat Industry, Chinese Ministry of Agriculture (CARS-3-1-19).

\section{LITERATURE CITED}

Chebil, A., K. Abbas, and A. Frija. 2014. Water use efficiency in irrigated wheat production systems in central Tunisia: A stochastic data envelopment approach. Journal of Agricultural Science 6(2):63-71. doi:10.5539/jas.v6n2p63.

CRGCST. 2001. Cooperative Research Group on Chinese Soil Taxonomy. Chinese Soil Taxonomy. Science Press, Beijing, China. 
Dong, B.D., L. Shi, C.H. Shi, Y.Z. Qiao, M.Y. Liu, and Z.B. Zhang. 2011. Grain yield and water use efficiency of two types of winter wheat cultivars under different water regimes. Agricultural Water Management 99:103-110. doi:10.1016/j.agwat.2011.07.013.

Du, T.S., S.Z. Kang, J.S. Sun, X.Y. Zhang, and J.H. Zhang. 2010. An improved water use efficiency of cereals under temporal and spatial deficit irrigation in north China. Agricultural Water Management 97:66-74. doi:10.1016/j.agwat.2009.08.011.

Duivenboodew, N.V., M. Pala, C. Studer, C.L. Bielders, and D.J. Beukes. 2000. Cropping systems and crop complementarity in dryland agriculture to increase soil water use efficiency: A review. Netherlands Journal of Agricultural Science 48:213-236. doi:10.1016/S1573-5214(00)80015-9.

Fang, Y., L. Liu, B.C. Xu, and F.M. Li. 2011. The relationship between competitive ability and yield stability in an old and a modern winter wheat cultivar. Plant Soil 347:7-23. doi:10.1007/ s11104-011-0780-4

Fereres, E., and M.A. Soriano. 2007. Deficit irrigation for reducing agricultural water use. Journal of Experimental Botany 58(2):147159. doi: $10.1093 / \mathrm{jxb} / \mathrm{erl} 165$.

Gan, Y.T., G.P. Lafond, and W.E. May. 2000. Grain yield and water use: Relative performance of winter vs. spring cereals in east-central Saskatchewan. Canadian Journal of Plant Science 80:533-541.

Gupta, N.K., S. Gupta, and A. Kumar. 2001. Effect of water stress on physiological attributes and their relationship with growth and yield of wheat cultivars at different stages. Journal of Agronomy and Crop Science 186:55-62. doi:10.5376/ijh.2013.03.0012.

Jalilian, J., S.A.M. Modarres-Sanavy, S.F. Saberali, and K. SadatAsilan. 2012. Effects of the combination of beneficial microbes and nitrogen on sunflower seed yields and seed quality traits under different irrigation regimes. Field Crops Research 127:26-34. doi:10.1016/j.fcr.2011.11.001.

Karrou, M., T. Oweis, R.A. EI. Enein, and M. Sherif. 2012. Yield and water productivity of maize and wheat under deficit and raised bed irrigation practices in Egypt. African Journal of Agricultural Research 7:1755-1760. doi:10.5897/ajar11.2109.

Lenka, S., A.K. Singh, and N.K. Lenka. 2009. Water and nitrogen interaction on soil profile water extraction and ET in maize-wheat cropping system. Agricultural Water Management 96:195-207. doi:10.1016/j.agwat.2008.06.014.

Li, Q.Q., Y.H. Chen, M.Y. Liu, X.B. Zhou, B.D. Dong, and S.L. Yu. 2007. Effect of irrigation to winter wheat on the soil moisture evapotranspiration, and water use efficiency of summer maize in North China. Transactions of the ASABE 50:2073-2080.

Li, Q.Q., B.D. Dong, Y.Z. Qiao, M.Y. Liu, and J.W. Zhang. 2010. Root growth, available soil water, and water-use efficiency of winter wheat under different irrigation regimes applied at different growth stages in North China. Agricultural Water Management 97:1676-1682. doi:10.1016/j.agwat.2010.05.025

Li, F.D., G.Y. Pan, C.Y. Tang, Q.Y. Zhang, and J.J. Yu. 2008. Recharge source and hydro-geochemical evolution of shallow groundwater in a complex alluvial fan system, southwest of North China Plain. Environmental Geology 55:1109-1122. doi:10.1007/ s00254-007-1059-1.

Liu, K., Y.H. Zhang, Z.M. Wang, H.Y. Feng, S.L. Zhou, L.Q. Lu, et al. 2011. Characteristics of water consumption in water-saving winter wheat and effects on the utilization of subsequent summer rainfall in the North China Plain. International Journal of Plant Production 5:167-180.

Marano, R.P., R.L. Maumary, L.N. Fernandez, and L.M. Rista. 2012. Epidemiology of the diseases of wheat under different strategies of supplementary irrigation. International Journal of Agronomy doi:10.1155/2012/407365.

Miranzadeh, H., Y. Emam, P. Pilesjö, and H. Seyyedi. 2011. Water use efficiency of four dryland wheat cultivars under different levels of nitrogen fertilization. Journal of Agricultural Science and Technology 13:843-854.
Monclus, R., M. Villar, C. Barbaroux, C. Bastien, R. Fichot, F.M Delmotte, et al. 2009. Productivity, water-use efficiency and tolerance to moderate water deficit correlate in 33 poplar genotypes from a Populus deltoids $\times$ Populus trichocarpa $\mathrm{F}_{1}$ progeny. Tree Physiology 29:1329-1339. doi:10.1093/treephys/tpp075.

Panda, R.K., S.K. Behera, and P.S. Kashyap. 2003. Effective management of irrigation water for wheat under stressed conditions. Agricultural Water Management 63(1):37-56. doi:10.1016/s0378-3774(03)00099-4.

Pask, A.J.D., and M.P. Reynolds. 2013. Breeding for yield potential has increased deep soil water extraction capacity in irrigated wheat Crop Science 53:2090-2104. doi:10.2135/cropsci2013.01.0011.

Rizza, F., J. Ghashghaieb, S. Meyerc, L. Matteud, A.M. Mastrangelod, and F.W. Badeck. 2012. Constitutive differences in water use efficiency between two durum wheat cultivars. Field Crops Research 125:49-60. doi:10.1016/j.fcr.2011.09.001.

Saeedipour, S. 2011. The relationship between the senescence induced by water deficits and $\mathrm{C}$ remobilization during grain filling in two wheat cultivars differing in drought resistance. African Journal of Agricultural Research 6:1990-2001.

Saeedipour, S., and F. Moradi. 2012. Relationship of endogenous $\mathrm{ABA}$ and IAA to accumulation of grain protein and starch in two winter wheat cultivars under post-anthesis water deficit. Journal of Agricultural Science 4:147-156. doi:10.5539/jas.v4n2p147.

Shao, H.B., L.Y. Chu, G. Wu, J.H. Zhang, and Z.H. Lu. 2007. Where is the road to bio-water saving for the globe? Colloids and Surfaces B: Biointerfaces 55:251-254. doi:10.1016/j.colsurfb.2006.12.001.

Song, L., F.M. Li, X.W. Fan, Y.C. Xiong, W.Q. Wang, X.B. Wu, et al. 2009. Soil water availability and plant competition affect the yield of spring wheat. European Journal of Agronomy 31:51-60. doi:10.1016/j.eja.2009.03.003.

Sun, H.Y., C.M. Liu, X.Y. Zhang, Y.J. Shen, and Y.Q. Zhang. 2006. Effects of irrigation on water balance, yield and WUE of winter wheat in the North China Plain. Agricultural Water Management 85(1-2):211-218. doi:10.1016/j.agwat.2006.04.008

Wang, Z.M., P. Wang, X.H. Li, J.M. Li, and L.Q. Lu. 2006. Principle and technology of water-saving, fertilizer-saving, high-yielding and simple cultivation in $\mathrm{w}$ inter $\mathrm{w}$ heat. Review of China Agricultural Science and Technology 8(5):38-44 (in Chinese).

Wang, H.X., L. Zhang, W.R. Dawes, and C.M. Liu. 2001. Improving water use efficiency of irrigated crops in the North China Plainmeasurements and modelling. Agricultural Water Management 48:151-167. doi:10.1016/s0378-3774(00)00118-9.

Xue,Q.,Z.Zhu,J.T.Musick,B.A.Stewart, and D.A.Dusek.2003.Root growth and water uptake in winter wheat under deficit irrigation. Plant and Soil 257:151-161. doi:10.1023/a:1026230527597.

Xue, Q., Z. Zhu, J.T. Musick, B.A. Stewart, and D.A. Dusek. 2006 Physiological mechanisms contributing to the increased water-use efficiency in winter wheat under deficit irrigation. Journal of Plant Physiology 163:154-164. doi:10.1016/j.jplph.2005.04.026.

Yang, Z.J., F. Chen, L.G. Shi, and X.Y. Wen. 2013. Responses of photosynthetic characteristics of winter wheat cultivars released in different decades to water deficit in north china plain. Acta Agronomica Sinica 39:693-703 (in Chinese).

Yang, Y.H., M. Watanabe, X.Y. Zhang, J.Q. Zhang, Q.X. Wang, and S. Hayashi. 2006. Optimizing irrigation management for wheat to reduce groundwater depletion in the piedmont region of the Taihang Mountains in the North China Plain. Agricultural Water Management 82:25-44. doi:10.1016/j.agwat.2005.07.020.

Yu, Z.W., S.S. Yue, C.G. Shen, W. Zhang, and S.L. Yu. 1995. Effect on senescence of flag leaf in winter wheat under high yield - low norm irrigation conditions. Acta Agronomica Sinica 21:503-508 (in Chinese).

Zhang, X.Y., S.Y. Chen, H.Y. Sun, Y.M. Wang, and L.W. Shao. 2010a.Water use efficiency and associated traits in winter wheat cultivars in the North China Plain. Agricultural Water Management 97:1117-1125. doi:10.1016/j.agwat.2009.06.003. 
Zhang, Y.Q., K. Eloise, Q. Yu, C.M. Liu, Y.J. Shen, and H.Y. Sun. 2004b. Effect of soil water deficit on evapotranspiration, crop yield, and water use efficiency in the North China Plain. Agricultural Water Management 64:107-122. doi:10.1016/s03783774(03)00201-4.

Zhang, J.F., D.L. Mauzerall, T. Zhu, S. Liang, M. Ezzati, and J.V. Remais. 2010b. Environmental health in China: progress towards clean air and safe water. Lancet 375:1110-1119. doi:10.1016/ s0140-6736(10)60062-1.

Zhang, X.Y., D. Pei, and S.Y. Chen. 2004a. Root growth and soil water utilization of winter wheat in the North China Plain. Hydrological Processes 18:2275-2287. doi:10.1002/hyp.5533.

Zhang, X.Y., D. Pei, S.Y. Chen, H.Y. Sun, and Y.H. Yang. 2006. Performance of double-cropped winter wheat-summer maize under minimum irrigation in the North China plain. Agronomy Journal 98:1620-1626. doi:10.2134/agronj2005.0358.
Zhang, J.Y., J.S. Sun, A.W. Duan, J.L. Wang, X.J. Shen, and X.F. Liu. 2007. Effects of different planting patterns on water use and yield performance of winter wheat in the Huang-Huai-Hai plain of China. Agricultural Water Management 92:41-47. doi:10.1016/j. agwat.2007.04.007.

Zhang, X.Y., Y.Z. Wang, H.Y. Sun, S.Y. Chen, and L.W. Shao. 2013. Optimizing the yield of winter wheat by regulating water consumption during vegetative and reproductive stages under limited water supply. Irrigation Science 31:1103-1112. doi:10.1007/s00271-012-0391-8. 